\title{
Population structure and genomic inbreeding in nine Swiss dairy cattle populations
}

\author{
Heidi Signer-Hasler ${ }^{1 *} \mathbb{D}$, Alexander Burren ${ }^{1}$, Markus Neuditschko², Mirjam Frischknecht ${ }^{1,3}$, Dorian Garrick ${ }^{4}$, \\ Christian Stricker ${ }^{5}$, Birgit Gredler ${ }^{3}$, Beat Bapst ${ }^{3}$ and Christine Flury ${ }^{1}$
}

\begin{abstract}
Background: Domestication, breed formation and intensive selection have resulted in divergent cattle breeds that likely exhibit their own genomic signatures. In this study, we used genotypes from 27,612 autosomal single nucleotide polymorphisms to characterize population structure based on 9214 sires representing nine Swiss dairy cattle populations: Brown Swiss (BS), Braunvieh (BV), Original Braunvieh (OB), Holstein (HO), Red Holstein (RH), Swiss Fleckvieh (SF), Simmental (SI), Eringer (ER) and Evolèner (EV). Genomic inbreeding $\left(F_{\mathrm{ROH}}\right)$ and signatures of selection were determined by calculating runs of homozygosity $(\mathrm{ROH})$. The results build the basis for a better understanding of the genetic development of Swiss dairy cattle populations and highlight differences between the original populations (i.e. $\mathrm{OB}, \mathrm{SI}, \mathrm{ER}$ and $\mathrm{EV}$ ) and those that have become more popular in Switzerland as currently reflected by their larger populations (i.e. BS, BV, $\mathrm{HO}, \mathrm{RH}$ and SF).
\end{abstract}

Results: The levels of genetic diversity were highest and lowest in the SF and BS breeds, respectively. Based on $F_{S T}$ values, we conclude that, among all pairwise comparisons, BS and $\mathrm{HO}(0.156)$ differ more than the other pairs of populations. The original Swiss cattle populations OB, SI, ER, and EV are clearly genetically separated from the Swiss cattle populations that are now more common and represented by larger numbers of cows. Mean levels of $F_{\text {ROH }}$ ranged from 0.027 (ER) to 0.091 (BS). Three of the original Swiss cattle populations, ER ( $\left.F_{\mathrm{ROH}}: 0.027\right)$, OB ( $\left.F_{\mathrm{ROH}}: 0.029\right)$, and SI ( $\left.F_{\mathrm{ROH}}: 0.039\right)$, showed low levels of genomic inbreeding, whereas it was much higher in EV ( $F_{\mathrm{ROH}}$ : 0.074). Private signatures of selection for the original Swiss cattle populations are reported for BTA4, 5, 11 and 26.

Conclusions: The low levels of genomic inbreeding observed in the original Swiss cattle populations ER, OB and SI compared to the other breeds are explained by a lesser use of artificial insemination and greater use of natural service. Natural service results in more sires having progeny at each generation and thus this breeding practice is likely the major reason for the remarkable levels of genetic diversity retained within these populations. The fact that the EV population is regionally restricted and its small census size of herd-book cows explain its high level of genomic inbreeding.

\section{Background}

Domestication, breed formation and intensive selection have led to divergent cattle breeds that likely exhibit distinctive genomic signatures of selection. Over recent years, molecular tools have contributed to a better

\footnotetext{
*Correspondence: heidi.signer@bfh.ch

1 School of Agricultural, Forest and Food Sciences, Bern University

of Applied Sciences, Zollikofen, Switzerland

Full list of author information is available at the end of the article
}

understanding of domestication and have identified a growing list of genes involved in adaptation [1]. Numerous studies using various methods and types of molecular markers to characterize genetic diversity within and between breeds have been published [2]. Genome-wide single nucleotide polymorphism (SNP) data has pushed the characterization of genetic diversity in cattle breeds forward. Decker et al. [3] assessed the population structure of 134 cattle breeds using $50 \mathrm{~K}$ SNPs and identified 
three major groups of cattle: Asian indicine, Eurasian taurine, and African taurine. Comparing North American Brown Swiss, Jersey and Holstein bulls, Melka and Schenkel [4] found that the highest genetic differentiation was between Brown Swiss and Holstein bulls. A study that used multi-dimensional scaling to assess the population structure of Italian Brown, Italian Holstein, Piedmontese, Marchigiana and Italian Pezzata Rossa bulls showed that these five populations were separated from each other, with the Italian Brown showing a small group of outliers [5]. In a French study, French Holstein, Normande and Montbéliarde bulls were assigned to isolated clusters, whereas the population-specific average $F_{\mathrm{ST}}$ was highest for Holstein [6]. Another study that investigated population structure, selection signatures and demographic history in cattle was published by Oroczo-ter Wengel et al. [7].

Genome-wide SNP data allow the characterization of runs of homozygosity ( $\mathrm{ROH}$ ) which can quantify the extent of inbreeding in diploid individuals [8]. Several studies in cattle [9-13] showed that long and uninterrupted $\mathrm{ROH}$ were suitable to estimate genomic inbreeding coefficients. Knowledge of the $\mathrm{ROH}$ provides new possibilities to manage inbreeding in livestock species and could be used for optimal allocation of resources and maintenance of genetic variation in intensely selected bovine breeds [14]. Furthermore, $\mathrm{ROH}$ can be used to analyze inbreeding depression in cattle populations for which there is no reliable ancestry information [15-17].

The availability of genome-wide SNPs has led to the development of several methods for the detection of genomic regions that have undergone selection $[18,19]$. Numerous studies using different methods for such analyses have been reported for cattle [5, 20-31]. GutiérrezGil et al. [32] reviewed 21 studies and reported 1049 signatures of selection across 37 European cattle breeds. They highlighted private regions that were specific to single breeds, which may contain genes that are involved in the occurrence of unique phenotypic characteristics of such breeds. Randhawa et al. [33] performed a metaanalysis of 56 studies on signatures of selection that represented more than 70,000 animals from 90 bovine breeds. These authors reported hotspots of signatures of selection in the bovine genome, and identified regions under selection that were common to multiple breeds, some occurring in regions that contain single genes of known major effects and others that cover genes known to influence polygenic traits.

Genetic diversity is an intrinsic factor that influences the adaptive capacity and resilience of populations [34]. The objective of our study was to assess population structure using 27,612 autosomal SNPs in nine Swiss dairy cattle populations including Brown Swiss (BS), Braunvieh
(BV), Original Braunvieh (OB), Holstein (HO), Red Holstein (RH), Swiss Fleckvieh (SF), Simmental (SI), Eringer (ER) and Evolèner (EV). In addition, we derived $\mathrm{ROH}$ and compared marker-based measures of inbreeding with pedigree-based inbreeding coefficients. For the derivation of potential signatures of selection, we calculated the $d_{i}$ statistic [35], which is a function of pairwise $F_{\mathrm{ST}}$ values [36] between population $i$ and the remaining populations to highlight potential loci that lead to differentiation between these populations. With the introduction of artificial insemination in the 1960's, the OB population was introgressed with BS individuals from North America resulting in the current BV population [37], while genetic material of both $\mathrm{RH}$ and HO breeds were introduced into the SI population, resulting in the SF population [38]. Our findings help to improve our understanding of the genetic background of Swiss dairy cattle populations and enable the identification of differences between the original Swiss breeds (i.e. OB, SI, ER and EV) and those breeds that are now characterized by larger populations (i.e. BS, BV, HO, RH and SF).

\section{Methods \\ Data and data preparation}

The data analyzed consisted of 9214 bulls from nine Swiss cattle populations (see Additional file 1: Table S1), which were genotyped with Illumina Bovine $50 \mathrm{k}$ v1 or v2 SNP BeadChips (BS, BV, OB, HO, RH, SF, SI), Illumina 50k iSelect (ER) or Illumina Bovine 777k BeadChip (EV). In spite of the differences in SNP content between these BeadChips, 46,146 autosomal SNPs were common to the four genotyping arrays and these were used for quality control with PLINK 1.9 [39, 40]. In a first step, SNPs were filtered based on their calling rate (-geno 0.1) and 41,131 SNPs fulfilled this criterion. Second, for each population separately, SNPs with a minor allele frequency (-maf) lower than $1 \%$ or SNPs deviating from Hardy-Weinberg equilibrium (-hwe 0.0001) were removed. After this filtering step for all nine populations, 27,612 common SNPs were available for further analyses (see Additional file 2: Table S2).

\section{Population structure}

We used various parameters to characterize population structure and genetic diversity. When not specified, these were obtained from PLINK $1.9[39,40]$. The proportion of observed heterozygosity was estimated from the observed homozygosity (-het) as: 1 - number of observed homozygous loci/number of non missing loci. Genomic relationships represented by the genomewide proportions of shared identical-by-descent alleles were derived for each pair of samples using the -genome option. Multi-dimensional scaling (MDS) of pairwise 
genetic distances was used to identify relationships between populations (-cluster -mds-plot 2). Pairwise $F_{\mathrm{ST}}$ values between the nine cattle populations were calculated using the SNP and Variation Suite v8 (Golden Helix, Inc., Bozeman, MT, www.goldenhelix.com). A graphical representation of the phylogenetic relationships between the nine populations was obtained by using the commonly applied neighbor-joining (NJ) method, as implemented in the program SPLITSTREE4 [41]. We used the program ADMIXTURE [42] to determine the optimal number of $\mathrm{k}$ clusters, and to characterize individuals in terms of these clusters. Due to the available relationship structures (e.g. half-sib structures) and differences in sample size, it was not possible to perform an ADMIXTURE analysis for the full sample set. Thus, we randomly resampled 50 individuals from each of the BS, $\mathrm{BV}, \mathrm{OB}, \mathrm{HO}, \mathrm{RH}, \mathrm{SF}$ and SI populations, while considering all $57 \mathrm{EV}$ and ER animals, which resulted in 407 individuals. We used the software DISTRUCT [43] to draw a graphical representation of each cluster assignment by increasing $\mathrm{k}$ from 2 to 10 .

\section{Genomic inbreeding}

Genomic inbreeding coefficients for the 9214 bulls were derived by using the PLINK 1.9 [39, 40] option -het $\left(F_{\mathrm{HOM}}=\right.$ [number of observed homozygous loci - number of expected homozygous loci]/[number of nonmissing loci - number of expected homozygous loci]) and by using the option -homozyg $\left(F_{\mathrm{ROH}}\right)$ with the following non-default settings: at least 50 SNPs to define a ROH (calculated according to Purfield et al. [9]), minimum SNP density set to 1 per $100 \mathrm{~kb}$ (average density in our data was 1 SNP every $90.1 \mathrm{~kb}$ ), with a maximum gap length of $1800 \mathrm{~kb}$ (the maximum gap length in our data was $1737.1 \mathrm{~kb}$ ). A window was considered as a $\mathrm{ROH}$, if there were no heterozygous loci and no more than two missing genotypes for this region.

Inbreeding coefficients $\left(F_{\mathrm{ROH}}\right)$ for each breed were calculated according to McQuillan et al. [44]:

$$
F_{\mathrm{ROH}}=\sum \frac{L_{R O H}}{L_{A U T O}},
$$

where $L_{A U T O}$ is the length of the autosomal genome that spans SNP positions $[2,497,129 \mathrm{~kb}$ in the current study; (see Additional file 2: Table S2)]. Pedigree-based inbreeding coefficients $\left(F_{\text {PED }}\right)$ were derived for the 9214 bulls based on pedigree data with the Software CFC [45]. $F_{\mathrm{PED}}$ and $F_{\mathrm{ROH}}$ were compared using linear regression and Pearson's correlation coefficients, across all animals or only for animals with at least 95\% known ancestors across the last five generations (pedigree completeness index, $\left.\mathrm{PCI}_{5 \mathrm{G}} \geq 0.95\right)$.

\section{Selection signatures}

The filtered data representing 9214 sires and 27,612 SNPs were used for the detection of signatures of selection. Due to the very limited number of samples and the close mutual relationships between the sampled individuals [46], ER and EV were pooled to infer signatures of selection.

Wright's $F_{\mathrm{ST}}$ values were calculated for all 28 pairs of populations using the plink command - fst. Then, $d_{i \_S N P}$ values were calculated for each SNP and population as: $d_{i \_S N P}=\sum_{j \neq i} \frac{F_{\mathrm{ST}}^{i j}-E\left[F_{\mathrm{ST}}^{i j}\right]}{s d\left[F_{\mathrm{ST}}^{i j}\right]}$, where $E\left[F_{\mathrm{ST}}^{i j}\right]$ and $s d\left[F_{\mathrm{ST}}^{i j}\right]$ denote the expected value and standard deviation of $F_{\mathrm{ST}}$ between populations $i$ and $j$ calculated based on all 27,612 SNPs, as proposed by Akey et al. [35].

The $d_{i}$ values were averaged for SNPs in 2435 nonoverlapping $1-\mathrm{Mb}$ windows. Windows with less than four SNPs were discarded, which resulted on an average of 11.27 SNPs per window (maximum $=26 \mathrm{SNPs}$ ). If the average $d_{i}$ value of a window exceeded the 99th percentile of the empirical distribution of $d_{i}$, it was considered significant, resulting in 25 windows as putative signatures of selection for each breed.

All genes that were present within $1 \mathrm{Mb}$ up- or downstream of the middle position of the 25 population-specific significant windows were identified with the NCBI MAPVIEWER (http://www.ncbi.nlm.nih.gov/projects/ mapview/; NCBI annotation release 104). Knowledge of population-specific characteristics (see Additional file 1: Table S1) and insights from the literature were combined to select the candidate genes that are reported in this study.

\section{Results \\ Population structure}

The mean within-population genomic relationship ranged from 0.044 (SF) to 0.155 (BS), whereas the mean observed heterozygosity ranged from 0.357 (BS) to 0.399 (SF) (Table 1 and see Additional file 3: Figures S1 and S2). Within BV, BS and SI, some highly related pairs of animals were found (see Additional file 4: Figure S3).

Multi-dimensional scaling (MDS) of pairwise genetic distances was used to visualize relationships between the 9214 bulls. Plotting the first dimension versus the second dimension revealed five distinct clusters (Fig. 1). The original Swiss cattle populations OB, SI, ER, and $\mathrm{EV}$ are clearly separated from the larger, more common Swiss cattle populations and are positioned in-between the clusters of BV, BS and SF, RH, HO. An ADMIXTURE analysis (see Additional file 5: Figure S4) similarly demonstrated that OB, SI, ER and EV form distinct populations. In addition, these results further support the 
Table 1 Number of sires, average genomic relationship and average observed heterozygosity in nine Swiss dairy cattle populations

\begin{tabular}{|c|c|c|c|}
\hline Population & Number of sires & $\begin{array}{l}\text { Mean genomic relationship }{ }^{a}( \pm S D) \\
(p<2.2 e-16)^{*}\end{array}$ & $\begin{array}{l}\text { Mean observed heterozygosity ( } \pm \text { SD) } \\
(p<2.2 \mathrm{e}-16)^{*}\end{array}$ \\
\hline BS & 281 & $0.155( \pm 0.067)^{\mathrm{A}}$ & $0.357( \pm 0.015)^{A}$ \\
\hline BV & 3386 & $0.113( \pm 0.053)^{B}$ & $0.364( \pm 0.016)^{B}$ \\
\hline $\mathrm{OB}$ & 167 & $0.082( \pm 0.064)^{C}$ & $0.383( \pm 0.012)^{C}$ \\
\hline $\mathrm{HO}$ & 2568 & $0.083( \pm 0.057)^{\mathrm{D}}$ & $0.377( \pm 0.014)^{\mathrm{D}}$ \\
\hline $\mathrm{RH}$ & 1960 & $0.060( \pm 0.052)^{\mathrm{E}}$ & $0.385( \pm 0.015)^{E}$ \\
\hline SF & 547 & $0.044( \pm 0.051)^{F}$ & $0.399( \pm 0.013)^{F}$ \\
\hline SI & 248 & $0.124( \pm 0.063)^{G}$ & $0.367( \pm 0.012)^{B}$ \\
\hline ER & 36 & $0.066( \pm 0.024)^{E}$ & $0.381( \pm 0.007)^{C, D, E}$ \\
\hline EV & 21 & $0.091( \pm 0.120)^{C, D}$ & $0.360( \pm 0.024)^{A, B}$ \\
\hline
\end{tabular}

BS Brown Swiss, BV Braunvieh, OB Original Braunvieh, HO Holstein, RH Red Holstein, SF Swiss Fleckvieh, SI Simmental, ER Eringer, EV Evolèner

* $p$ value, Kruskal-Wallis test, R: kruskal.test()

a Pairwise genomic relationships were calculated for all individuals from all populations together

$A, B, C, D, E, F, G$ Different letters indicate significant Bonferroni-adjusted differences between breeds, as assessed with the R-package DUNN.TEST

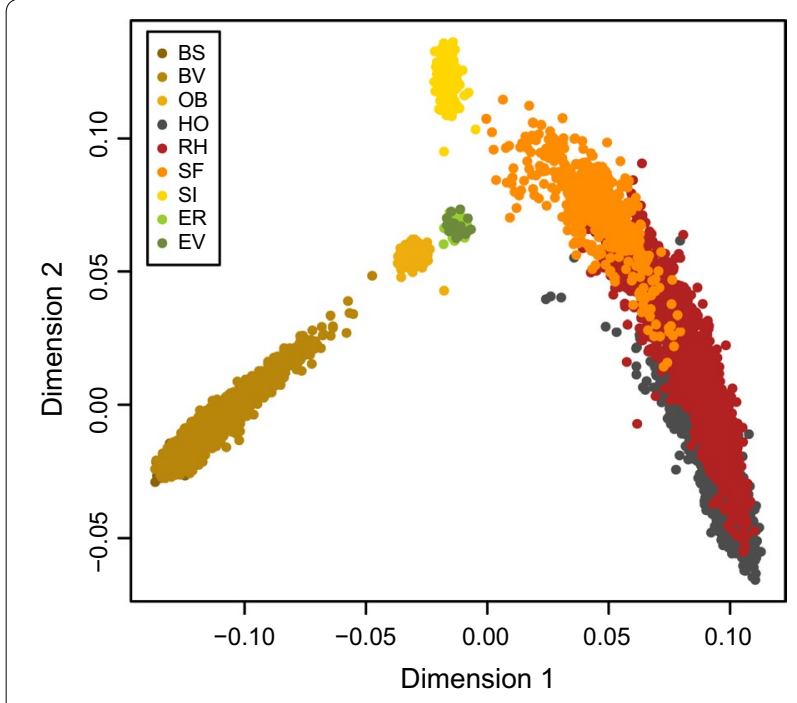

Fig. 1 MDS-plot of dimension 1 versus dimension 2

previously described genetic proximity between EV and ER, between BS and BV and between HO, RH and SF, respectively.

The $F_{\mathrm{ST}}$ values ranged from $0.007(\mathrm{BS} / \mathrm{BV})$ to 0.156 $(\mathrm{BS} / \mathrm{HO})$ in the investigated populations (see Additional file 6: Table S3). The NJ tree (see Additional file 7: Figure S5) illustrates the phylogenetic relationships between the nine populations based on $F_{\mathrm{ST}}$ distances. These results are in agreement with the clustering from the MDS plot (Fig. 1) and with the results from the ADMIXTURE analysis (see Additional file 5: Figure S4).
$\mathrm{ROH}$ and genomic inbreeding

For 34 bulls, we detected no ROH segments (Table 2). The proportion of animals without a single $\mathrm{ROH}$ was highest in SF (2.9\%), followed by OB (1.8\%). In total, $135,640 \mathrm{ROH}$ segments were identified across the nine populations and all the individuals. The average number of $\mathrm{ROH}$ per animal was largest for BS (21.0) and smallest for SF (7.1). The average sum of the lengths of $\mathrm{ROH}$ per animal ranged from $66.2 \mathrm{Mb}$ (ER) to $226.4 \mathrm{Mb}$ (BS). Additional file 8: Figure S6 represents the number and total length of $\mathrm{ROH}$ for the nine populations.

Long $\mathrm{ROH}$ are expected in inbred animals with recent common ancestors whereas short $\mathrm{ROH}$ reflect more distant common ancestors. Five- to $10-\mathrm{Mb}$ long $\mathrm{ROH}$ were the most frequent in all populations, ranging from $43.2 \%$ (BS) to 47.5\% (SI) (see Additional file 9: Figure S7). Comparison across the nine populations showed that, for ER, $\mathrm{OB}$ and SI, the highest proportion of $\mathrm{ROH}$ was for 1- to 5 - $\mathrm{Mb}$ long $\mathrm{ROH}$ (34.8\% in ER, $29.5 \%$ in OB and $29.2 \%$ in $\mathrm{SI}$ ) and the lowest proportion for $10-$ to $15-\mathrm{Mb} \mathrm{ROH}$ (11.0\% in SI, $11.5 \%$ in ER and $12.8 \%$ in OB).

The number of $\mathrm{ROH}$ per chromosome tended to increase with increasing chromosome length, with the largest numbers of $\mathrm{ROH}$ observed on BTA1 and 6 and the smallest on BTA27 and 5 (see Additional file 10: Table S4).

Overall, although available pedigree information for ER and EV was incomplete compared to the complete pedigree data for the seven other populations, ER and EV had the lowest average PCI and consequently, the lowest average pedigree inbreeding $\left(F_{\mathrm{PED}}\right)$ estimates (Table 3$)$. 
Table 2 Number of sires with and without identified runs of homozygosity (ROH), total number of ROH per population, average number of ROH per population and average sum of the lengths of ROH for each of the nine Swiss dairy cattle populations

\begin{tabular}{|c|c|c|c|c|c|}
\hline Population & $\begin{array}{l}\text { Number of sires } \\
\text { without } \mathrm{ROH}\end{array}$ & $\begin{array}{l}\text { Number of sires } \\
\text { with detected ROH }\end{array}$ & $\begin{array}{l}\text { Total number } \\
\text { of ROH }\end{array}$ & $\begin{array}{l}\text { Avg. number of ROH } \\
\text { segments } \\
\text { (min-max) } \\
(p<2.2 \mathrm{e}-16)^{*}\end{array}$ & $\begin{array}{l}\text { Avg. sum of the lengths } \\
\text { of ROH segments }(\mathrm{Mb}) \\
\text { (min-max) } \\
(p<2.2 \mathrm{e}-16)^{*}\end{array}$ \\
\hline BS & 0 & 281 & 5892 & $21.0(6-38)^{A}$ & $226.4(39.2-505.1)^{\mathrm{A}}$ \\
\hline BV & 7 & 3379 & 62,783 & $18.6(1-38)^{B}$ & $184.6(3.7-638.3)^{B}$ \\
\hline OB & 3 & 164 & 1382 & $8.4(1-27)^{C}$ & $73.7(4.9-234.6)^{C}$ \\
\hline $\mathrm{HO}$ & 5 & 2563 & 36,498 & $14.2(2-32)^{\mathrm{D}}$ & $145.2(8.2-696.3)^{\mathrm{D}}$ \\
\hline $\mathrm{RH}$ & 3 & 1957 & 21,979 & $11.2(1-30)^{\mathrm{E}}$ & $112.1(4.0-460.8)^{\mathrm{E}}$ \\
\hline SF & 16 & 531 & 3772 & $7.1(1-21)^{C}$ & $75.6(3.4-273.5)^{C}$ \\
\hline SI & 0 & 248 & 2703 & $10.9(2-26)^{\mathrm{E}}$ & $96.6(13.2-299.8)^{F}$ \\
\hline ER & 0 & 36 & 305 & $8.5(2-15)^{C, E}$ & $66.2(9.6-171.5)^{C, F}$ \\
\hline EV & 0 & 21 & 326 & $15.5(6-30)^{\mathrm{B}, \mathrm{D}}$ & $185.7(35.0-371.3)^{A, B, D}$ \\
\hline Total & 34 & 9180 & 135,640 & & \\
\hline
\end{tabular}

BS Brown Swiss, BV Braunvieh, OB Original Braunvieh, HO Holstein, RH Red Holstein, SF Swiss Fleckvieh, SI Simmental, ER Eringer, EV Evolèner

* $p$ value, Kruskal-Wallis test, $\mathrm{R}$ : kruskal.test()

$A, B, C, D, E, F$ Different letters indicate significant Bonferroni-adjusted differences between breeds, as assessed in the R-package DUNN.TEST

Table 3 Number of sires, pedigree completeness index for five generations $\left(\mathrm{PCl}_{5 \mathrm{G}}\right)$, average pedigree inbreeding $\left(F_{\mathrm{PED}}\right)$ and average genomic inbreeding $\left(F_{\mathrm{HOM}}, F_{\mathrm{ROH}}\right.$ and $\left.F_{\mathrm{ROH}>5 \mathrm{Mb}}\right)$ for nine Swiss dairy cattle populations

\begin{tabular}{|c|c|c|c|c|c|c|}
\hline Population & $\begin{array}{l}\text { Number } \\
\text { of sires }\end{array}$ & Avg. $\mathrm{PCl}_{5 \mathrm{G}}$ & $\begin{array}{l}\text { Avg. } F_{\text {PED }} \\
( \pm S D)(p<2.2 e-16)^{*}\end{array}$ & $\begin{array}{l}\text { Avg. } F_{\text {HOM }} \\
( \pm S D)(p<2.2 e-16)^{*}\end{array}$ & $\begin{array}{l}\text { Avg. } F_{\mathrm{ROH}} \\
( \pm \mathrm{SD})(\mathrm{p}<2.2 \mathrm{e}-16)^{*}\end{array}$ & $\begin{array}{l}\text { Avg. } F_{\mathrm{ROH}>5 M b} \\
( \pm \mathrm{SD})(\mathrm{p}<2.2 \mathrm{e}-16)^{*}\end{array}$ \\
\hline BS & 281 & 0.993 & $0.071( \pm 0.028)^{\mathrm{A}}$ & $0.115( \pm 0.037)^{\mathrm{A}}$ & $0.091( \pm 0.029)^{A}$ & $0.084( \pm 0.029)^{\mathrm{A}}$ \\
\hline BV & 3386 & 0.995 & $0.059( \pm 0.023)^{B}$ & $0.100( \pm 0.039)^{B}$ & $0.074( \pm 0.028)^{B}$ & $0.067( \pm 0.027)^{B}$ \\
\hline OB & 167 & 0.992 & $0.023( \pm 0.017)^{C}$ & $0.052( \pm 0.029)^{C}$ & $0.029( \pm 0.017)^{C}$ & $0.025( \pm 0.016)^{c}$ \\
\hline $\mathrm{HO}$ & 2568 & 0.991 & $0.057( \pm 0.023)^{\mathrm{D}}$ & $0.066( \pm 0.035)^{\mathrm{D}}$ & $0.058( \pm 0.025)^{\mathrm{D}}$ & $0.053( \pm 0.025)^{\mathrm{D}}$ \\
\hline $\mathrm{RH}$ & 1960 & 0.993 & $0.042( \pm 0.022)^{\mathrm{E}}$ & $0.047( \pm 0.037)^{C}$ & $0.045( \pm 0.023)^{\mathrm{E}}$ & $0.041( \pm 0.023)^{\mathrm{E}}$ \\
\hline SF & 547 & 0.992 & $0.027( \pm 0.020)^{C}$ & $0.012( \pm 0.033)^{\mathrm{E}}$ & $0.029( \pm 0.021)^{c}$ & $0.027( \pm 0.021)^{\mathrm{B}}$ \\
\hline SI & 248 & 0.991 & $0.028( \pm 0.024)^{C}$ & $0.092( \pm 0.030)^{B}$ & $0.039( \pm 0.023)^{F}$ & $0.033( \pm 0.022)^{F}$ \\
\hline ER & 36 & 0.808 & $0.015( \pm 0.012)^{C}$ & $0.056( \pm 0.018)^{C, D}$ & $0.027( \pm 0.014)^{C, F}$ & $0.022( \pm 0.013)^{B, F}$ \\
\hline EV & 21 & 0.358 & $0.012( \pm 0.026)^{C}$ & $0.109( \pm 0.059)^{\mathrm{A}, \mathrm{B}}$ & $0.074( \pm 0.042)^{B, D}$ & $0.070( \pm 0.041)^{A, B, D}$ \\
\hline
\end{tabular}

BS Brown Swiss, BV Braunvieh, OB Original Braunvieh, HO Holstein, RH Red Holstein, SF Swiss Fleckvieh, SI Simmental, ER Eringer, EV Evolèner

* $p$ value, Kruskal-Wallis test, R: kruskal.test()

$A, B, C, D, E, F$ Different letters indicate significant Bonferroni-adjusted differences between breeds, as assessed in the R-package DUNN.TEST

Average $F_{\mathrm{PED}}$ was highest for BS (7.1\%), followed by BV $(5.9 \%)$ and $\mathrm{HO}(5.7 \%)$ and average genomic inbreeding $\left(F_{\mathrm{HOM}}, F_{\mathrm{ROH}}\right.$ and $\left.F_{\mathrm{ROH}>5 \mathrm{Mb}}\right)$ was highest for $\mathrm{BS}, \mathrm{BV}$ and EV. Average $F_{\mathrm{HOM}}$ and $F_{\mathrm{ROH}}$ were higher than $F_{\mathrm{PED}}$ for all populations. Genomic inbreeding was slightly lower or equal to $F_{\mathrm{PED}}$ in $\mathrm{HO}, \mathrm{RH}$ and $\mathrm{SF}$ when inbreeding was defined for long ROH using $F_{\mathrm{ROH}}>5 \mathrm{Mb}$.

Linear relationships between $F_{\mathrm{ROH}}$ and $F_{\mathrm{PED}}$ (Fig. 2) and between $F_{\mathrm{HOM}}$ and $F_{\mathrm{PED}}$ (see Additional file 11: Figure S8) were observed. Across all 9214 animals, the correlations between $F_{\mathrm{PED}}$ and $F_{\mathrm{ROH}}$ and between $F_{\mathrm{PED}}$ and $F_{\mathrm{HOM}}$ were significantly different from 0 with $\mathrm{r}$ equal to 0.70 $(\mathrm{p}<2.2 \mathrm{e}-16)$ and $0.67(\mathrm{p}<2.2 \mathrm{e}-16)$, respectively (see
Additional file 12: Tables S5 and S6) and the correlation between $F_{\mathrm{PED}}$ and $F_{\mathrm{ROH}>5 M b}$ was equal to 0.69 (results not shown).

For 12 chromosomes (i.e. BTA3, 4, 6, 10, 11, 12, 13, 18, $19,20,22$, and 29 ), at least $25 \%$ of the investigated animals within a population shared a $\mathrm{ROH}$ (see Additional file 13: Figure S9).

\section{Selection signatures}

For each population, 25 windows were considered to represent putative signatures of selection, which resulted in 200 significant windows across the eight investigated groups of populations, i.e. when ER and EV populations 


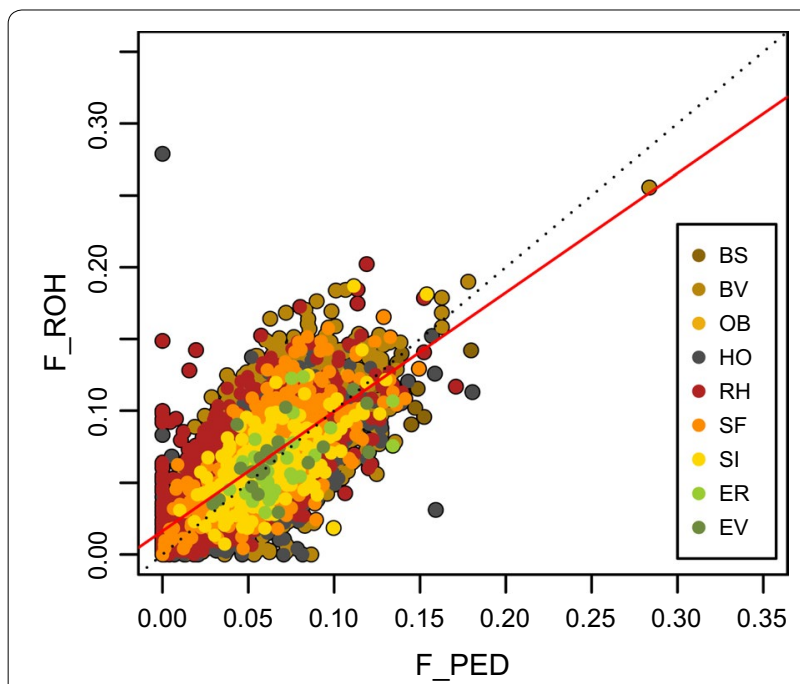

Fig. 2 Regression of $F_{\mathrm{PED}}$ on $F_{\mathrm{ROH}}$ for all 9214 individuals. Multiple R-squared: 0.49 . Red line is regression line $\left(F_{\mathrm{ROH}}=0.016+0.830 * F_{\mathrm{PED}}\right)$

were considered in the same group (see Additional file 14: Figure S10, Additional file 15: Table S7). Among these windows, 66 (33\%) were significant but private to only one population. The remaining 134 (67\%) windows were significant in two or more populations, with one extreme window on BTA14 showing significant $d_{i}$ values in all populations (Table 4 and see Additional file 15: Table S7). Across all groups and autosomes, BTA5 hosted the largest number of significant windows $(\mathrm{N}=33)$, followed by BTA6 $(\mathrm{N}=32)$, BTA18 $(\mathrm{N}=16)$ and BTA20 $(\mathrm{N}=15)$. Almost $50 \%$ of the significant windows are located on these four autosomes.

The 32 most prominent signatures of selection (e.g. windows with $d_{i}$ higher than 10) are in Table 4 . The window with the highest $d_{i}(25.7)$ was on BTA18 (14.2 Mb) in $\mathrm{HO}$ (Table 4). The same window had the second highest $d_{i}$ (24.3) in RH and was also significant in SF, SI and $\mathrm{OB}$. The window with the third highest $d_{i}(18.6)$ was on BTA14 (24.4 Mb) in RH. This latter window was significant in all populations and was previously reported to harbor signatures of selection (e.g. [31, 33, 47]).

The window with the fourth highest $d_{i}$ was on BTA11 $(68.6 \mathrm{Mb})$ in OB and was also significant in BV, SI, SF and $\mathrm{ER} / \mathrm{EV}$. It was previously reported in OB [48]. With a $d_{i}$ of 12.9, the preceding window (i.e. on BTA11 between 65.5 and $67.5 \mathrm{Mb}$ ) was also significant in $\mathrm{OB}$. A window with a significant $d_{i}$ higher than 14 was found on BTA16 (between 24.7 and $26.7 \mathrm{Mb}$ ) in BV and BS and was also significant in $\mathrm{OB}, \mathrm{RH}, \mathrm{SF}$ and SI. In the same region, another window with a $d_{i}$ higher than 10 was significant in BS (BTA16 between 26.5 and $28.5 \mathrm{Mb}$ ) and was also significant in $\mathrm{BV}$ and $\mathrm{OB}$.
Three strong signatures of selection (i.e. $d_{i}$ higher than 10) were observed for $\mathrm{HO}$ on BTA20, i.e. in windows spanning 29.2-31.2, 43.5-45.6 and 46.6-48.6 Mb. All three windows were also significant in $\mathrm{RH}$ whereas the third window was significant in SF and SI. In the top two significant windows that spanned 43.5-45.6 and 46.6-48.6 Mb on BTA20, we did not identify any candidate genes (Table 4 and see Additional file 15: Table S7). Remarkably, the proximal window (BTA20 between 30.5 and $32.5 \mathrm{Mb}$ ) that harbors the well-known GHR gene was not significant in $\mathrm{HO}$ but moderately significant in $\mathrm{RH}\left(d_{i}=7.4\right)$ and in SF $\left(d_{i}=5.9\right)$ (see Additional file 15: Table S7).

For ER/EV, two windows with $d_{i}$ of 13.4 were identified on BTA4 (between 53.4 and $55.4 \mathrm{Mb}$ ) and on BTA26 (between 21.5 and $23.5 \mathrm{Mb}$ ). The BTA26 window was also significant in $\mathrm{OB}$, another local Swiss cattle population. Among the nine loci localized in the region of the significant window on BTA4, no obvious candidate gene was identified. A second signature of selection on BTA4 (between 78.6 and $80.6 \mathrm{Mb}$ ) was private to ER/EV.

In SI, a window with a $d_{i}$ of 13.1 was observed on BTA6 (between 69.3 and $71.3 \mathrm{Mb}$ ) and was also significant in $\mathrm{BS}, \mathrm{BV}, \mathrm{HO}$ and SF. The KIT gene (BTA6: 71.8-71.9 Mb) is located near this region. Based on the filtered dataset, the available SNP density in this region was very limited. Similarly, the window on BTA5 (between 16.3 and $18.3 \mathrm{Mb}$ ) was significant in five populations (BV, OB, SF and ER/EV). On BTA5, two additional windows (between 55.6 and $57.6 \mathrm{Mb}$ and between 60.5 and $62.5 \mathrm{Mb}$ ) were highly significant in the sampled SI individuals, with the first window (55.6-57.6 Mb) being also significant in the RH and SF populations. Two other windows on BTA5 were significant: i.e. the window between 75.1 and $77.1 \mathrm{Mb}$ in SI, BS and BV and the window between 76.4 and $78.4 \mathrm{Mb}$ in BS, BV and $\mathrm{OB}$.

Additional windows with a $d_{i}$ higher than 10 were detected on BTA5 (between 46.2 and $48.2 \mathrm{Mb}$ and between 60.5 and $62.5 \mathrm{Mb}$ ) and BTA6 (between 32.4 and 34.4 $\mathrm{Mb}$ and between 77.4 and $79.4 \mathrm{Mb}$ ) but no candidate genes were identified in any of these windows.

\section{Discussion}

\section{Population structure}

We assessed the population structure of nine Swiss cattle populations by using 27,612 autosomal SNPs and showed that genetic diversity was highest in SF and lowest in BS. Based on $F_{\mathrm{ST}}$, BS and $\mathrm{HO}$ were more differentiated (0.156) than all other pairs of populations (see Additional file 6: Table S3), which agrees with the results reported by Melka and Schenkel [4]. The genetic differentiation was lowest in BS and BV (0.007), followed by $\mathrm{HO}$ and $\mathrm{RH}$ (0.016), RH and SF (0.025), ER and EV (0.048), HO and SF 
Table 4 Genomic coordinates (chromosome and start- and stop-position) of the 32 windows with $d_{i}$ higher than 10, the corresponding population (in brackets, other populations for which the window was significant) and their candidate genes

\begin{tabular}{|c|c|c|c|c|c|c|c|}
\hline BTA & $\begin{array}{l}\text { Start posi- } \\
\text { tion }\end{array}$ & End position & $d_{i}$ & $\begin{array}{l}\text { Population (other popula- } \\
\text { tions) }\end{array}$ & Candidate genes & Associated trait & References \\
\hline 4 & $53,358,285$ & $55,358,285$ & 13.424 & ER/EV & & & \\
\hline 4 & $78,602,192$ & $80,602,192$ & 10.036 & ER/EV & INHBA & Feed intake & [71] \\
\hline 5 & $16,275,624$ & $18,275,624$ & 10.760 & $\mathrm{SF}(\mathrm{BV}, \mathrm{OB}, \mathrm{ER} / \mathrm{EV})$ & KITLG & & {$[80]$} \\
\hline 5 & $46,225,174$ & $48,225,174$ & 11.852 & $\mathrm{RH}(\mathrm{HO}, \mathrm{SF}, \mathrm{ER} / \mathrm{EV})$ & & & \\
\hline 5 & $46,225,174$ & $48,225,174$ & 11.511 & $\mathrm{HO}(\mathrm{RH}, \mathrm{SF}, \mathrm{ER} / \mathrm{EV})$ & & & \\
\hline 5 & $55,558,224$ & $57,558,224$ & 13.108 & $\mathrm{SI}(\mathrm{RH}, \mathrm{SF})$ & STAT6 & $\begin{array}{l}\text { Growth efficiency, carcass } \\
\text { traits }\end{array}$ & {$[81]$} \\
\hline 5 & $60,520,962$ & $62,520,962$ & 12.197 & SI & & & \\
\hline 5 & $75,148,807$ & $77,148,807$ & 10.435 & $\mathrm{SI}(\mathrm{BV}, \mathrm{BS})$ & SYT10 & Longevity & {$[82]$} \\
\hline 5 & $76,432,958$ & $78,432,958$ & 10.735 & $\mathrm{BS}(\mathrm{BV}, \mathrm{OB})$ & SYT10 & Longevity & {$[82]$} \\
\hline 6 & $32,407,621$ & $34,407,621$ & 11.691 & $\mathrm{BV}(\mathrm{BS})$ & & & \\
\hline 6 & $69,255,003$ & $71,255,003$ & 13.069 & $\mathrm{SI}(\mathrm{BV}, \mathrm{BS}, \mathrm{HO}, \mathrm{SF})$ & KIT & White spotting & {$[80]$} \\
\hline 6 & $77,416,656$ & $79,416,656$ & 12.928 & $\mathrm{HO}(\mathrm{BS}, \mathrm{BV}, \mathrm{RH}, \mathrm{SF}, \mathrm{BS}, \mathrm{BV})$ & & & \\
\hline 6 & $77,416,656$ & $79,416,656$ & 11.932 & $\mathrm{RH}(\mathrm{BS}, \mathrm{BV}, \mathrm{HO}, \mathrm{SF})$, & & & \\
\hline 11 & $65,512,895$ & $67,512,895$ & 12.856 & $\mathrm{OB}$ & PROKR1 & Fertility & {$[48]$} \\
\hline 11 & $67,608,705$ & $69,608,705$ & 17.985 & $\mathrm{OB}(\mathrm{BV}, \mathrm{SF}, \mathrm{SI}, \mathrm{ER} / \mathrm{EV})$ & CAPN14, CAPN13, LBH, & Fertility, meat quality & {$[48,75,76]$} \\
\hline 11 & $67,608,705$ & $69,608,705$ & 11.660 & $\mathrm{SI}(\mathrm{BV}, \mathrm{OB}, \mathrm{SF}, \mathrm{ER} / \mathrm{EV})$ & $\begin{array}{l}\text { LCLAT1, GFPT1, EHD3, } \\
\text { GMCL1, PCBP1 }\end{array}$ & & \\
\hline 14 & $23,392,111$ & $25,392,111$ & 18.647 & $\begin{array}{l}\mathrm{RH}(\mathrm{BS}, \mathrm{BV}, \mathrm{OB}, \mathrm{HO}, \mathrm{SF}, \mathrm{SI}, \\
\mathrm{ER} / \mathrm{EV})\end{array}$ & PLAG1, CHCHDT, LYN, TGS1 & Stature, fertility & {$[69,70]$} \\
\hline 14 & $23,392,111$ & $25,392,111$ & 15.509 & $\begin{array}{l}\text { SF (BS, BV, OB, HO, RH, SI, } \\
\text { ER/EV) }\end{array}$ & & & \\
\hline 14 & $23,392,111$ & $25,392,111$ & 15.050 & $\begin{array}{l}\mathrm{HO}(\mathrm{BS}, \mathrm{BV}, \mathrm{OB}, \mathrm{RH}, \mathrm{SF}, \mathrm{SI}, \\
\mathrm{ER} / \mathrm{EV})\end{array}$ & & & \\
\hline 14 & $23,392,111$ & $25,392,111$ & 10.466 & $\begin{array}{l}\mathrm{OB}(\mathrm{BS}, \mathrm{BV}, \mathrm{HO}, \mathrm{RH}, \mathrm{SF}, \mathrm{SI}, \\
\mathrm{ER} / \mathrm{EV})\end{array}$ & & & \\
\hline 16 & $24,736,714$ & $26,736,714$ & 15.161 & $\mathrm{BV}(\mathrm{BS}, \mathrm{OB}, \mathrm{RH}, \mathrm{SF}, \mathrm{SI})$ & $H L X$ & Feed efficiency & {$[83]$} \\
\hline 16 & $24,736,714$ & $26,736,714$ & 14.335 & $\mathrm{BS}(\mathrm{BV}, \mathrm{OB}, \mathrm{RH}, \mathrm{SF}, \mathrm{SI})$ & & & \\
\hline 16 & $26,450,435$ & $28,450,435$ & 10.846 & $\mathrm{BS}(\mathrm{BV}, \mathrm{OB})$ & TLR5, CAPN8, CAPN2 & $\begin{array}{l}\text { Disease resistance, meat } \\
\text { quality }\end{array}$ & {$[75,84-86]$} \\
\hline 18 & $13,233,845$ & $15,233,845$ & 25.720 & $\mathrm{HO}(\mathrm{OB}, \mathrm{RH}, \mathrm{SF}, \mathrm{SI})$ & MC1R, SLC7A5, CDH15, & Coat color & {$[31-33,87]$} \\
\hline 18 & $13,233,845$ & $15,233,845$ & 24.272 & $\mathrm{RH}(\mathrm{OB}, \mathrm{HO}, \mathrm{SF}, \mathrm{SI})$ & & & \\
\hline 18 & $13,233,845$ & $15,233,845$ & 10.451 & $\mathrm{SF}(\mathrm{OB}, \mathrm{HO}, \mathrm{RH}, \mathrm{SI})$ & & & \\
\hline 18 & $14,373,569$ & $16,373,569$ & 13.715 & $\mathrm{RH}(\mathrm{HO}, \mathrm{SF})$ & FANCA & & {$[87]$} \\
\hline 20 & $29,194,786$ & $31,194,786$ & 14.835 & $\mathrm{HO}(\mathrm{RH})$ & MRPS30, FGF10 & $\begin{array}{l}\text { Milk yield. Protein percent- } \\
\text { age }\end{array}$ & {$[88,89]$} \\
\hline 20 & $43,561,002$ & $45,561,002$ & 10.593 & $\mathrm{HO}(\mathrm{RH})$ & & & \\
\hline 20 & $46,566,649$ & $48,566,649$ & 12.743 & $\mathrm{HO}(\mathrm{RH}, \mathrm{SF}, \mathrm{SI})$ & $\mathrm{CDH}$ & Clinical mastitis & [90] \\
\hline 20 & $46,566,649$ & $48,566,649$ & 10.759 & $\mathrm{RH}(\mathrm{HO}, \mathrm{SF}, \mathrm{SI})$ & $\mathrm{CDH} 9$ & Clinical mastitis & {$[90]$} \\
\hline 26 & $21,528,510$ & $23,528,510$ & 13.360 & $\mathrm{ER} / \mathrm{EV}(\mathrm{OB})$ & FGF8, SCD & $\begin{array}{l}\text { Carcass quality, fertility, fatty } \\
\text { acid composition }\end{array}$ & {$[72-74]$} \\
\hline
\end{tabular}

(0.052). These findings are in concordance with the MDS plot (Fig. 1), which shows five distinct clusters: (1) BS and BV, (2) OB, (3) ER and EV, (4) SI, and (5) SF, RH and HO, and with the results from the ADMIXTURE analysis. The original Swiss cattle populations OB, SI, ER, and EV that are currently less common are clearly separated from the more common cattle populations. Combining the MDS and ADMIXTURE results with the $F_{\mathrm{ST}}$ values of 0.111 for BS and OB and 0.094 for BV and OB, the clear separation between $\mathrm{OB}$ and $\mathrm{BS}$ and $\mathrm{BV}$ is obvious. The $\mathrm{OB}$ population represents the original population of Brown cattle without the influence of the recently introgressed 
BS individuals. However, OB is ancestral to the BS population, which was formed in the USA from animals that were obtained in Switzerland between 1869 and 1910 [37]. According to Porter et al. [49], the BS breed was founded based on 167 of these imported individuals. In the USA, this BS founder population was improved with a specific selection focus on milk yield. Introgression of BS back into OB began in Switzerland in the 1960s, which coincided with the introduction of artificial insemination and subsequently led to the BV population. The use of imported BS sires in BV is still common and thus leads to BV animals with various levels of BS genes [37, 50]. SF is a crossbreed between SI and RH (see Additional file 5: Figure S4). Based on the $F_{\mathrm{ST}}$ values, $\mathrm{SF}$ is more distant from SI (0.072) than from RH (0.024). This is also apparent in the MDS plot, where SF is more distant from SI than from RH. The comparison of withinpopulation diversity, which was quantified either from genomic relationships or from observed heterozygosity, showed that the two extreme populations were SF and BS with the highest diversity observed in SF and the lowest diversity in BS. This is not surprising for two reasons: $\mathrm{SF}$ is well known as a composite population of SI and $\mathrm{RH}$ [38] and, as indicated above, BS can be traced back to a few $\mathrm{OB}$ founder animals that were subsequently strongly selected for milk production. The considerable loss of genetic diversity within the BS population was previously reported based on pedigree information [37].

\section{Genomic inbreeding}

In recent years, several studies have investigated $\mathrm{ROH}$ in cattle. Purfield et al. [9] found similar correlations between $F_{\mathrm{ROH}}$ and $F_{\mathrm{PED}}$ using both 50k and HD SNP data and thus, they concluded that 50k SNP data are sufficient to identify $\mathrm{ROH}$ and to estimate genomic inbreeding. Because the parameters used to detect $\mathrm{ROH}$ vary among analyses, it is not easy to compare results from different $\mathrm{ROH}$ studies. The setting of the parameters used to derive $\mathrm{ROH}$ is crucial to account for the effects of SNP density correctly. Using the PLINK 1.9 [39, 40] default parameter of 100 consecutive SNPs to call a ROH, would not have identified any $\mathrm{ROH}$ less than $5 \mathrm{Mb}$ in our data (results not shown). Therefore, the minimum number of SNPs to identify ROH should be defined according to the available SNP density. One such approach was proposed by Lencz et al. [51] and applied by Purfield et al. [9]. Their conclusions were supported by the recent study of Rodriguez-Ramilo and Fernandez [52] who showed that the four parameters, minimum length, minimum number of SNPs, minimum SNP density and maximum distance between two adjacent SNPs, each influence the identification of $\mathrm{ROH}$ and therefore the estimation of $F_{\mathrm{ROH}}$. In our study, we defined $\mathrm{ROH}$ as tracts of homozygous SNPs that spanned a minimum of 50 consecutive loci, in regions with a minimum density of one SNP every $100 \mathrm{~kb}$, a maximum gap length of $1800 \mathrm{~kb}$, while allowing up to two missing genotypes per window but no heterozygous loci. Most $\mathrm{ROH}$ were observed in the length class of 5 to $10 \mathrm{Mb}$ (see Additional file 9: Figure S7). This contrasts with the findings of Marras et al. [12] who reported that the 1 - to $2-\mathrm{Mb}$ long $\mathrm{ROH}$ were the most frequent in all populations, ranging from $~ 50 \%$ in Italian Brown to $\sim 80 \%$ in Piedmontese. The difference between these results is mainly explained by the different minimum number of SNPs used to define a ROH. In our data, frequencies higher than $28 \%$ were observed for the shortest $\mathrm{ROH}$ length class $(1$ to $5 \mathrm{Mb}$ ) in the three local populations OB, SI and ER. This could be due to "old inbreeding" resulting from previous bottlenecks that occurred when the breed was created during the second half of the nineteenth century. However, the frequencies of the longest $\mathrm{ROH}$, i.e. length classes of 25 to $30 \mathrm{Mb}$ and more than $30 \mathrm{Mb}$ were highest in $\mathrm{EV}$, which indicates recent inbreeding. This is not surprising because this population is specific to a given region and its census size is less than 200 registered herd-book cows (see Additional file 1: Table S1).

Mean levels of $F_{\mathrm{ROH}}$ ranged from 0.027 (ER) to 0.091 (BS). The results for BS (0.091) and BV (0.074) are consistent with their low levels of genetic diversity. In contrast, the three original Swiss cattle populations ER $\left(F_{\mathrm{ROH}}\right.$ : 0.027), OB ( $\left.F_{\mathrm{ROH}}: 0.029\right)$, and SI ( $\left.F_{\mathrm{ROH}}: 0.039\right)$ had lower levels of inbreeding. Natural service is still commonly used in these three populations (see Additional file 1: Table S1), which requires the use of more sires at each generation than artificial insemination. This is considered as the major reason for the remarkably low levels of genomic inbreeding within these populations, although they have been closed populations for a long time.

$F_{\mathrm{ROH}}$ directly reflects the level of homozygosity and is not influenced by allele frequencies, unlike $F_{\mathrm{HOM}}$, which depends on allele frequencies and thus on sampling [53]. $F_{\mathrm{HOM}}$ can even be negative for some individuals, which indicates that they are less inbred than the average population [54]. Nevertheless, since $F_{\mathrm{HOM}}$ is a single point approach, it does not rely on the availability of SNP positions [55]. For $\mathrm{ROH}$ analyses, the knowledge of SNP positions is an important prerequisite. The fact that $F_{\mathrm{ROH}}$ does not depend on the sampling procedure is a great advantage since $\mathrm{ROH}$ can be identified for every single individual. Furthermore, with $F_{\mathrm{ROH}}$, recent and ancient inbreeding can be distinguished $[8,56]$.

Our results clearly showed a linear relationship between $F_{\mathrm{ROH}}$ and $F_{\mathrm{PED}}$ and between $F_{\mathrm{HOM}}$ and $F_{\mathrm{PED}}$ (Fig. 2 and see Additional file 11: Figure S8, Additional file 12: Tables S5 and S6). The correlations between $F_{\mathrm{ROH}}$ 
and $F_{\mathrm{PED}}$ presented here are in concordance with published results in cattle $[9,12]$ and other species with similar pedigree completeness such as goats [57] and horses [58].

Several of the regions in which we identified $\mathrm{ROH}$ that were common to at least $25 \%$ of the animals (see Additional file 13: Figure S9) confirm previously reported data. For example, on BTA6 we detected a ROH that was present in at least $25 \%$ of the investigated BS and BV bulls and located in the same region $(\sim 91 \mathrm{Mb})$ where Schwarzenbacher [14] claimed that up to $50 \%$ of Brown Swiss bulls carried a ROH. A possible explanation for the obvious inbreeding in this region is that it harbors several QTL for economically relevant traits in cattle such as protein yield [59], clinical mastitis [60-62], milking speed [63] and udder traits [64, 65]. On BTA13, more than $30 \%$ of the BS bulls and $25 \%$ of the BV bulls had a $\mathrm{ROH}$ in the region between 30 and $40 \mathrm{Mb}$, which agrees with the studies of Minozzi et al. [66] who detected SNPs in this region $(\sim 30.5 \mathrm{Mb})$ that were significantly associated with days to first service in Holstein and of Stella et al. [23] who reported signatures of selection on this chromosome at $\sim 33.0 \mathrm{Mb}$ in dairy breeds. On BTA19, we found that up to $35 \%$ of the BS bulls had a $\mathrm{ROH}$ between 45 and $50 \mathrm{Mb}$, which is concordant with the high level of genetic differentiation at $\sim 46 \mathrm{Mb}$ reported by the Bovine HapMap Consortium [22]. Furthermore, in a Braunvieh population, Rothammer et al. [48] detected a signature of selection in the region between $\sim 47$ and $51 \mathrm{Mb}$ on BTA19, which harbours the GH1 gene, a potential candidate gene for dairy cattle production traits. On BTA10, we showed that up to $30 \%$ of the $\mathrm{HO}$ bulls had a $\mathrm{ROH}$ between 50 and $60 \mathrm{Mb}$. Previously, in a study on German Holstein, Kühn et al. [67] identified putative QTL for somatic cell content and non-return rate at 90 days (paternal effect) on BTA10 between 34.7 and $56.9 \mathrm{Mb}$. Furthermore, based on integrated haplotype scoring (iHs) on Holstein data, the Bovine HapMap Consortium [22] reported recent positive selection at $\sim 53 \mathrm{Mb}$ on BTA10. Finally, on BTA18, up to $30 \%$ of the RH bulls investigated in our study had a ROH between 10 and $20 \mathrm{Mb}$, which is a region that includes the well-known MC1R gene and where composite signatures of selection were detected in several breeds (e.g. [32]).

\section{Signatures of selection}

Various studies on signatures of selection in cattle using genome-wide SNPs have been published and for dairy cattle populations such as Holstein, Red Holstein and Brown Swiss, major signatures of selection have been described (e.g. [31]). In their study, Rothammer et al. [48] included local cattle populations and derived signatures of selection for the OB population based on $50 \mathrm{k}$ genotypes from 35 individuals. Signatures of selection were also identified in the SI populations by Fan et al. [29] and Zhao et al. [31], among others. To our knowledge, our study is the first one to consider data from ER and $\mathrm{EV}$ populations, which are well-known to have a long selection history with emphasis on milk, meat and fighting ability traits $[49,68]$. Thus, our study that includes samples from OB, SI, and ER/EV breeds investigates for the first time signatures of selection for dairy cattle populations in Switzerland.

Genes known to be linked to strong signatures of selection in cattle such as KIT, MC1R, ABCG2, LCORL/ NCAPG and PLAG1 [33] are fully supported by our data. These signatures of selection were significant in many of the analyzed breeds with the most extreme signal around PLAG1 being significant in all eight population groups. The pleiotropic nature of this region [69] and a potentially interesting mutation for bovine stature [70] are understood to be major drivers that underlie the strong signature of selection that was observed among all Swiss dairy populations.

Selection at the POLL locus, the MSTN and DGAT1 genes, and the genes from the casein cluster have not left any recognizable signatures of selection among the investigated populations. Based on phenotypic evidence, it is presumed that the region that includes the casein cluster is under selection but that it has not yet reached fixation in any of the Swiss populations. We did not detect any signature of selection in the DGAT1 gene, possibly because of the low SNP density in this region of BTA14. Since the Swiss dairy cattle populations are historically horned and not influenced by any double-muscled breed, the lack of signatures of selection around the POLL locus and the MSTN gene was not surprising.

The common ancestries between BS, BV and $\mathrm{OB}$, between HO, RH and SF and between SF and SI are well known and were previously described $[37,38]$. Thus, the detection of private signatures of selection in the original Swiss SI, OB and ER/EV populations was of major interest for this study. On BTA4, two prominent signatures of selection (between 53.4 and $55.4 \mathrm{Mb}$ and between 78.6 and $80.6 \mathrm{Mb}$ ) were detected only in the ER/EV population. Although we identified no obvious candidate gene in the BTA4 window between 53.4 and $55.4 \mathrm{Mb}$ based either on the literature or functional evidence, a metaassembly of signatures of selection suggested that this region is under selection in European breeds [33]. For the second BTA4 window between 78.6 and $80.6 \mathrm{Mb}$, the INHBA gene represents a relevant candidate gene since it is involved in feed intake in Angus cattle [71]. We detected a strong signature of selection in ER/EV that was also significant in OB in the BTA26 region between 21.5 and $23.5 \mathrm{Mb}$, which harbors genes such as FGF8 
and $S C D$. These two candidate genes are known to influence carcass quality, fatty acid composition of meat and milk and fertility traits [72-74]. Due to their pleiotropic effects on these economically important traits, and to the strength of the signal, further investigations on the functional consequences of this signature of selection are required. Two windows on BTA11 (between 65.5 and $67.5 \mathrm{Mb}$ and between 67.6 and $69.6 \mathrm{Mb}$ ) harbored highly significant signatures of selection in the OB population. Previously, Rothammer et al. [48] assigned the most extended signature of selection for the $\mathrm{OB}$ population to this region and proposed genes associated with fertility as possible candidate genes. However, other genes such as CAPN14, CAPN13, LBH and LCLAT1 genes that are located in this region and influence meat quality $[75,76]$ should also be considered as candidate genes. For the SI population, two windows on BTA5 (between 55.6 and $57.6 \mathrm{Mb}$ and between 60.5 and $62.5 \mathrm{Mb}$ ) are particularly interesting. Between these two windows, another region that spans the PMEL and GDF11 genes is characterized by a $d_{i}$ higher than 20 in SI (results not shown) but it was omitted from the final derivation of signatures of selection, because it did not fulfill the minimal SNP density of four loci per window. Based on these results, it is suggested that the extended BTA5 region between 55.6 and $62.5 \mathrm{Mb}$ played an important role in the differentiation of SI. Besides many other loci, we propose STAT5, GDF11 and $P M E L$ as potential drivers of the differentiation of SI from other cattle populations.

For several of the significant regions representing signatures of selection, we did not identify any candidate genes either due to the lack of genes with functional evidence in these regions (e.g. BTA4 between 53.4 and $55.4 \mathrm{Mb}$; Table 4) or to poor annotation. Zhao et al. [31] suggested that regions that do not appear to contain genes may play an important role in adaptation and may be elucidated in the future with an improved annotation of the bovine genome. Based on limited marker densities in our data and the finding of Kemper et al. [47] that response to selection is usually based on small changes in frequency at many loci, only loci with major effects due to strong selection could be detected here. The collection and analysis of thousands of phenotypes together with high-density genotypes may be necessary to disentangle the genetic basis of adaptation to the alpine environment of SI, OB and ER/EV populations.

\section{Conclusions}

The original Swiss cattle populations OB, SI, ER and EV are genomically distinct from the more common dairy cattle populations. We report several private signatures of selection in regions that harbor genes such as INHBA, STAT6, PROKR1, CAPN14, CAPN13, FGF8 and SCD for these original populations. The low levels of genomic inbreeding observed in OB, SI and ER might be explained by the continued use of natural service sires, which is likely the major reason for their remarkably high level of genetic diversity although these populations have been closed for a long time. The regional specificity and the small census size of herd-book cows in EV explain its high level of genomic inbreeding. Optimum genetic contribution selection [77-79] may be an option to avoid inbreeding in the more popular Swiss dairy cattle represented by larger populations and in which the proportion of artificial insemination is higher than $90 \%$.

\section{Additional files}

Additional file 1: Table S1. Number of genotyped bulls per population with their minimum and maximum birth year, as well as number of breeding animals per population, responsible breeding organization and breedspecific characteristics such as major use, breeding goal and proportion of artificial insemination.

Additional file 2: Table S2. Number of SNPs per chromosome, range covered by SNPs per chromosome and in total.

Additional file 3: Figure S1. Boxplots of genomic relationships. Figure S2. Boxplots of observed heterozygosity.

Additional file 4: Figure S3. Levelplot of pair-wise genomic relationship within and between populations.

Additional file 5: Figure S4. Distruct plot of the Admixture results for the nine Swiss cattle populations. Cross-validation error was lowest for $k=9$ and 10 , which indicates that $k=9$ or 10 is the optimal number of clusters.

Additional file 6: Table S3. $F_{\mathrm{ST}}$-values with $95 \%$ confidence interval in brackets in the lower triangular part.

Additional file 7: Figure S5. Neighbour joining (NJ) tree based on $F_{S T}$ distances.

Additional file 8: Figure S6. Relationship between the number of $\mathrm{ROH}$ and the total length of genome in $\mathrm{ROH}$.

Additional file 9: Figure S7. Distribution of the number of ROH in different length classes and for each population.

Additional file 10: Table S4. Number of $\mathrm{ROH}$ per chromosome and population.

Additional file 11: Figure S8. Regression of $F_{\mathrm{PED}}$ on $F_{\mathrm{HOM}}$ for all 9214 individuals. Multiple R-squared: 0.45 .

Additional file 12: Table S5. Correlations between $F_{\mathrm{PED}}$ and $F_{\mathrm{ROH}}$ and between $F_{\text {PED }}$ and $F_{\text {HOM }}$ including all animals. Table S6. Correlations between $F_{\mathrm{PED}}$ and $F_{\mathrm{ROH}}$ and between $F_{\mathrm{PED}}$ and $F_{\mathrm{HOM}}$ including only animals with $\mathrm{PCl}>0.95$.

Additional file 13: Figure S9. Proportion of animals with this SNP within a ROH.

Additional file 14: Figure S10. Genomic distribution of the $d_{i}$ statistic for all 1-Mb windows across all autosomes and the eight groups of populations. The dashed red line denotes the 99th percentile for each population group (BS: Brown Swiss, BV: Braunvieh, OB: Original Braunvieh; HO: Holstein, RH: Red Holstein, SF: Swiss Fleckvieh, SI: Simmental, ER/EV: Eringer and Evolèner).

Additional file 15: Table S7. Genomic coordinates (chromosome and start- and end-position) of all significant windows, the population for which $d_{i}$ was calculated, and genes within this region. 


\section{Authors' contributions}

$\mathrm{BG}, \mathrm{BB}$ and $\mathrm{CF}$ conceived and designed the study. $\mathrm{HS}, \mathrm{AB}$ and $\mathrm{CF}$ analyzed the data. MN and MF contributed analysis tools. HS, DG, CS and CF wrote the paper. All authors read and approved the final manuscript.

\section{Author details}

1 School of Agricultural, Forest and Food Sciences, Bern University of Applied Sciences, Zollikofen, Switzerland. ${ }^{2}$ Agroscope, Swiss National Stud Farm, Avenches, Switzerland. ${ }^{3}$ Qualitas AG, Zug, Switzerland. ${ }^{4}$ Massey University, Hamilton, New Zealand. ${ }^{5}$ agn Genetics, Davos, Switzerland.

\section{Acknowledgements}

This work was performed within the framework of the Swiss Low Input Genetics (SLIG) project. We would like to thank the Swiss Commission for Technology and Innovation (CTI) for funding this project, the Swiss cattle breeding organizations and Swissgenetics for providing genotypes and for their support of the study.

\section{Competing interests}

The authors declare that they have no competing interests.

\section{Availability of data and materials}

The data analyzed during the current study are not publicly available but are available from the corresponding author on reasonable request.

\section{Consent for publication}

Not applicable.

\section{Ethics approval and consent to participate}

Not applicable.

\section{Funding}

This study was funded by the Swiss Commission for Technology and Innovation (Grant Number: 14745.2 PFLS-LS).

\section{Publisher's Note}

Springer Nature remains neutral with regard to jurisdictional claims in published maps and institutional affiliations.

Received: 22 December 2016 Accepted: 26 October 2017

Published online: 07 November 2017

\section{References}

1. FAO. The second report on the state of the world's animal genetic resources for food and agriculture. Rome: FAO; 2015.

2. Lenstra JA, Groeneveld LF, Eding H, Kantanen J, Williams JL, Taberlet $P$, et al. Molecular tools and analytical approaches for the characterization of farm animal genetic diversity. Anim Genet. 2012;43:483-502.

3. Decker JE, McKay SD, Rolf MM, Kim J, Molina Alcala A, Sonstegard TS, et al. Worldwide patterns of ancestry, divergence, and admixture in domesticated cattle. PLoS Genet. 2014;10:e1004254.

4. Melka MG, Schenkel FS. Analysis of genetic diversity in Brown Swiss, Jersey and Holstein populations using genome-wide single nucleotide polymorphism markers. BMC Res Notes. 2012;5:161.

5. Mancini G, Gargani M, Chillemi G, Nicolazzi EL, Marsan PA, Valentini A et al. Signatures of selection in five Italian cattle breeds detected by a 54 K SNP panel. Mol Biol Rep. 2014;41:957-65.

6. Flori L, Fritz S, Jaffrezic F, Boussaha M, Gut I, Heath S, et al. The genome response to artificial selection: a case study in dairy cattle. PLoS One. 2009;4:e6595

7. Orozco-terWengel P, Barbato M, Nicolazzi E, Biscarini F, Milanesi M, Davies W, et al. Revisiting demographic processes in cattle with genome-wide population genetic analysis. Front Genet. 2015;6:191

8. Curik I, Ferenčaković M, Sölkner J. Inbreeding and runs of homozygosity: a possible solution to an old problem. Livest Sci. 2014;166:26-34.

9. Purfield DC, Berry DP, McParland S, Bradley DG. Runs of homozygosity and population history in cattle. BMC Genet. 2012;13:70.
10. Ferenčaković M, Sölkner J, Curik I. Estimating autozygosity from highthroughput information: effects of SNP density and genotyping errors. Genet Sel Evol. 2013:45:42.

11. Ferenčaković M, Hamzic E, Gredler B, Solberg TR, Klemetsdal G, Curik I, et al. Estimates of autozygosity derived from runs of homozygosity: empirical evidence from selected cattle populations. J Anim Breed Genet. 2013;130:286-93.

12. Marras G, Gaspa G, Sorbolini S, Dimauro C, Ajmone-Marsan P, Valentini $A$, et al. Analysis of runs of homozygosity and their relationship with inbreeding in five cattle breeds farmed in Italy. Anim Genet. 2015:46:110-21.

13. Gurgul A, Szmatola T, Topolski P, Jasielczuk I, Zukowski K, BugnoPoniewierska M. The use of runs of homozygosity for estimation of recent inbreeding in Holstein cattle. J Appl Genet. 2016;57:527-30.

14. Schwarzenbacher $\mathrm{H}$. Analysis of genome regions showing strong inbreeding in Brown Swiss and Fleckvieh cattle. Interbull Bull. 2011;44:130-3.

15. Bjelland DW, Weigel KA, Vukasinovic N, Nkrumah JD. Evaluation of inbreeding depression in Holstein cattle using whole-genome SNP markers and alternative measures of genomic inbreeding. J Dairy Sci. 2013;96:4697-706.

16. Pryce JE, Haile-Mariam M, Goddard ME, Hayes BJ. Identification of genomic regions associated with inbreeding depression in Holstein and Jersey dairy cattle. Genet Sel Evol. 2014;46:71.

17. Howard JT, Maltecca C, Haile-Mariam M, Hayes BJ, Pryce JE. Characterizing homozygosity across United States, New Zealand and Australian Jersey cow and bull populations. BMC Genomics. 2015:16:187.

18. de Simoni Gouveia JJ, da Silva MVGB, Paiva SR, de Oliveira SMP. Identification of selection signatures in livestock species. Genet Mol Biol. 2014;37:330-42.

19. Qanbari S, Simianer H. Mapping signatures of positive selection in the genome of livestock. Livest Sci. 2014;166:133-43.

20. Barendse W, Harrison BE, Bunch RJ, Thomas MB, Turner LB. Genome wide signatures of positive selection: the comparison of independent samples and the identification of regions associated to traits. BMC Genomics. 2009;10:178.

21. Hayes BJ, Chamberlain AJ, Maceachern S, Savin K, McPartlan H, MacLeod I, et al. A genome map of divergent artificial selection between Bos taurus dairy cattle and Bos taurus beef cattle. Anim Genet. 2009;40:176-84.

22. Bovine HapMap Consortium, Gibbs RA, Taylor JF, van Tassell CP, Barendse W, Eversole KA, et al. Genome-wide survey of SNP variation uncovers the genetic structure of cattle breeds. Science. 2009:324:528-32.

23. Stella A, Ajmone-Marsan P, Lazzari B, Boettcher P. Identification of selection signatures in cattle breeds selected for dairy production. Genetics. 2010;185:1451-61.

24. Qanbari S, Pimentel ECG, Tetens J, Thaller G, Lichtner P, Sharifi AR, et al. A genome-wide scan for signatures of recent selection in Holstein cattle. Anim Genet. 2010;41:377-89.

25. Qanbari S, Gianola D, Hayes B, Schenkel F, Miller S, Moore S, et al. Application of site and haplotype-frequency based approaches for detecting selection signatures in cattle. BMC Genomics. 2011:12:318.

26. Qanbari S, Pausch H, Jansen S, Somel M, Strom TM, Fries R, et al. Classic selective sweeps revealed by massive sequencing in cattle. PLoS Genet. 2014;10:e1004148.

27. Schwarzenbacher $\mathrm{H}$, Dolezal M, Flisikowski $K$, Seefried $F$, Wurmser $\mathrm{C}$ Schlötterer $C$, et al. Combining evidence of selection with association analysis increases power to detect regions influencing complex traits in dairy cattle. BMC Genomics. 2012;13:48.

28. Ramey HR, Decker JE, McKay SD, Rolf MM, Schnabel RD, Taylor JF. Detection of selective sweeps in cattle using genome-wide SNP data. BMC Genomics. 2013;14:382.

29. Fan H, Wu Y, Qi X, Zhang J, Li J, Gao X, et al. Genome-wide detection of selective signatures in Simmental cattle. J Appl Genet. 2014;55:343-51.

30. Bomba L, Nicolazzi EL, Milanesi M, Negrini R, Mancini G, Biscarini F, et al. Relative extended haplotype homozygosity signals across breeds reveal dairy and beef specific signatures of selection. Genet Sel Evol. 2015;47:25

31. Zhao F, McParland S, Kearney F, Du L, Berry DP. Detection of selection signatures in dairy and beef cattle using high-density genomic information. Genet Sel Evol. 2015:47:49. 
32. Gutierrez-Gil B, Arranz JJ, Wiener P. An interpretive review of selective sweep studies in Bos taurus cattle populations: identification of unique and shared selection signals across breeds. Front Genet. 2015;6:167.

33. Randhawa IAS, Khatkar MS, Thomson PC, Raadsma HW. A meta-assembly of selection signatures in cattle. PLoS One. 2016;11:e0153013.

34. Hoffmann I. Adaptation to climate change-exploring the potential of locally adapted breeds. Animal. 2013;7:346-62.

35. Akey JM, Ruhe AL, Akey DT, Wong AK, Connelly CF, Madeoy J, et al. Tracking footprints of artificial selection in the dog genome. Proc Natl Acad Sci USA. 2010;107:1160-5.

36. Wright S. Isolation by distance. Genetics. 1943;28:114-38.

37. Hagger C. Estimates of genetic diversity in the brown cattle population of Switzerland obtained from pedigree information. J Anim Breed Genet. 2005;122:405-13.

38. Khayatzadeh N, Meszaros G, Utsunomiya YT, Garcia JF, Schnyder U, Gredler B, et al. Locus-specific ancestry to detect recent response to selection in admixed Swiss Fleckvieh cattle. Anim Genet. 2016;47:637-46.

39. Purcell S, Neale B, Todd-Brown K, Thomas L, Ferreira MAR, Bender D, et al. PLINK: a tool set for whole-genome association and population-based linkage analyses. Am J Hum Genet. 2007;81:559-75.

40. Chang CC, Chow CC, Tellier LC, Vattikuti S, Purcell SM, Lee JJ. Secondgeneration PLINK: rising to the challenge of larger and richer datasets. Gigascience. 2015;4:7.

41. Huson DH, Bryant D. Application of phylogenetic networks in evolutionary studies. Mol Biol Evol. 2006;23:254-67.

42. Alexander DH, Novembre J, Lange K. Fast model-based estimation of ancestry in unrelated individuals. Genome Res. 2009;19:1655-64.

43. Rosenberg NA. DISTRUCT: a program for the graphical display of population structure. Mol Ecol Notes. 2004;4:137-8.

44. McQuillan R, Leutenegger A-L, Abdel-Rahman R, Franklin CS, Pericic M, Barac-Lauc L, et al. Runs of homozygosity in European populations. Am J Hum Genet. 2008;83:359-72.

45. Sargolzaei M, Iwaisaki H, Colleau JJ. CFC: a tool for monitoring genetic diversity. In: Proceedings of the 8th world congress on genetics applied to livestock production: 13-18 August 2006, Belo Horizonte; 2006.

46. Schmid M, Saitbekova N, Gaillard C, Dolf G. Genetic diversity in Swiss cattle breeds. J Anim Breed Genet. 1999;116:1-8.

47. Kemper KE, Saxton SJ, Bolormaa S, Hayes BJ, Goddard ME. Selection for complex traits leaves little or no classic signatures of selection. BMC Genomics. 2014;15:246

48. Rothammer S, Seichter D, Förster M, Medugorac I. A genome-wide scan for signatures of differential artificial selection in ten cattle breeds. BMC Genomics. 2013;14:908.

49. Porter V, Alderson L, Hall SJG, Sponenberg DP. Mason's world encyclopedia of livestock breeds and breeding. Wallingford: CABI; 2016.

50. Stergiadis S, Bieber A, Franceschin E, Isensee A, Eyre MD, Maurer V, et al. Impact of US brown swiss genetics on milk quality from low-input herds in Switzerland: interactions with grazing intake and pasture type. Food Chem. 2015;175:609-18.

51. Lencz T, Lambert C, DeRosse P, Burdick KE, Morgan TV, Kane JM, et al. Runs of homozygosity reveal highly penetrant recessive loci in schizophrenia. Proc Natl Acad Sci USA. 2007;104:19942-7.

52. Rodriguez-Ramilo ST, Fernández F. What do we mean by runs of homozygosity? Assessing effect of parameters involved in their detection. In: Book of Abstracts of the 67th Annual Meeting of the European Federation of Animal Science: 29 August-02 September 2016: Belfast; 2016.

53. Zhang Q, Guldbrandtsen B, Bosse M, Lund MS, Sahana G. Runs of homozygosity and distribution of functional variants in the cattle genome. BMC Genomics. 2015;16:542.

54. Wang J. Marker-based estimates of relatedness and inbreeding coefficients: an assessment of current methods. J Evol Biol. 2014;27:518-30.

55. Kardos M, Luikart G, Allendorf FW. Measuring individual inbreeding in the age of genomics: marker-based measures are better than pedigrees. Heredity (Edinb). 2015;115:63-72.

56. Kim E-S, Sonstegard TS, van Tassell CP, Wiggans G, Rothschild MF. The relationship between runs of homozygosity and inbreeding in Jersey cattle under selection. PLoS One. 2015;10:e0129967.

57. Burren A, Neuditschko M, Signer-Hasler H, Frischknecht M, Reber I, Menzi F, et al. Genetic diversity analyses reveal first insights into breedspecific selection signatures within Swiss goat breeds. Anim Genet 2016;47:727-39.
58. Burren A, Signer-Hasler H, Neuditschko M, Hunziker M, Gerber V, Schnider $D$, et al. Runs of homozygosity in four different horse breeds. In: Book of Abstracts of the 67th Annual Meeting of the European Federation of Animal Science: 29 August-02 September 2016: Belfast; 2016.

59. Sodeland M, Grove H, Kent M, Taylor S, Svendsen M, Hayes BJ, et al. Molecular characterization of a long range haplotype affecting protein yield and mastitis susceptibility in Norwegian Red cattle. BMC Genet. 2011;12:70.

60. Sodeland M, Kent MP, Olsen HG, Opsal MA, Svendsen M, Sehested E, et al. Quantitative trait loci for clinical mastitis on chromosomes 2, 6, 14 and 20 in Norwegian Red cattle. Anim Genet. 2011;42:457-65.

61. Sahana G, Guldbrandtsen B, Thomsen B, Holm LE, Panitz F, Brondum RF, et al. Genome-wide association study using high-density single nucleotide polymorphism arrays and whole-genome sequences for clinical mastitis traits in dairy cattle. J Dairy Sci. 2014;97:7258-75.

62. Nilsen H, Olsen HG, Hayes B, Nome T, Sehested E, Svendsen M, et al. Characterization of a QTL region affecting clinical mastitis and protein yield on BTA6. Anim Genet. 2009;40:701-12.

63. Guo J, Jorjani H, Carlborg O. A genome-wide association study using international breeding-evaluation data identifies major loci affecting production traits and stature in the Brown Swiss cattle breed. BMC Genet. 2012;13:82

64. Flury C, Boschung C, Denzler M, Bapst B, Schnyder U, Gredler B, et al. Genome-wide association study for 13 udder traits from linear type classification in cattle. In: Proceedings of the 10th world congress on genetics applied to livestock production: 17-22 August 2014, Vancouver; 2014.

65. Pausch $H$, Emmerling $R$, Schwarzenbacher $H$, Fries R. A multi-trait metaanalysis with imputed sequence variants reveals twelve QTL for mammary gland morphology in Fleckvieh cattle. Genet Sel Evol. 2016;48:14.

66. Minozzi G, Nicolazzi EL, Stella A, Biffani S, Negrini R, Lazzari B, et al. Genome wide analysis of fertility and production traits in Italian Holstein cattle. PLoS One. 2013;8:e80219.

67. Kühn C, Bennewitz J, Reinsch N, Xu N, Thomsen H, Looft C, et al. Quantitative trait loci mapping of functional traits in the German Holstein cattle population. J Dairy Sci. 2003;86:360-8.

68. Flury C, Tapio M, Sonstegard T, Drögemüller C, Leeb T, Simianer $\mathrm{H}$, et al. Effective population size of an indigenous Swiss cattle breed estimated from linkage disequilibrium. J Anim Breed Genet. 2010;127:339-47.

69. Fortes MRS, Deatley KL, Lehnert SA, Burns BM, Reverter A, Hawken RJ, et al. Genomic regions associated with fertility traits in male and female cattle: advances from microsatellites to high-density chips and beyond. Anim Reprod Sci. 2013;141:1-19.

70. Karim L, Takeda H, Lin L, Druet T, Arias JAC, Baurain D, et al. Variants modulating the expression of a chromosome domain encompassing PLAG1 influence bovine stature. Nat Genet. 2011;43:405-13.

71. Al-Husseini W, Gondro C, Quinn K, Herd RM, Gibson JP, Chen Y. Expression of candidate genes for residual feed intake in Angus cattle. Anim Genet. 2014;45:12-9.

72. Marques E, Nkrumah JD, Sherman EL, Moore SS. Polymorphisms in positional candidate genes on BTA14 and BTA26 affect carcass quality in beef cattle. J Anim Sci. 2009;87:2475-84.

73. Santos-Biase WKF, Biase FH, Buratini J Jr, Balieiro J, Watanabe YF, Accorsi MF, et al. Single nucleotide polymorphisms in the bovine genome are associated with the number of oocytes collected during ovum pick up. Anim Reprod Sci. 2012;134:141-9.

74. Oh DY, Jin MH, Lee YS, Ha JJ, Kim BK, Yeo JS, et al. Identification of stearoyl-CoA desaturase (SCD) gene iiteractions in Korean native cattle based on the multifactor-dimensionality reduction method. Asian-Australas J Anim Sci. 2013;26:1218-28.

75. Ouali A, Herrera-Mendez CH, Coulis G, Becila S, Boudjellal A, Aubry L, Sentandreu MA. Revisiting the conversion of muscle into meat and the underlying mechanisms. Meat Sci. 2006;74:44-58.

76. Ryu J, Lee C. Identification of contemporary selection signatures using composite log likelihood and their associations with marbling score in Korean cattle. Anim Genet. 2014;45:765-70.

77. Koenig S, Simianer H. Approaches to the management of inbreeding and relationship in the German Holstein dairy cattle population. Livest Sci. 2006;103:40-53. 
78. Sørensen MK, Sørensen AC, Baumung R, Borchersen S, Berg P. Optimal genetic contribution selection in Danish Holstein depends on pedigree quality. Livest Sci. 2008;118:212-22.

79. Sonesson AK, Woolliams JA, Meuwissen THE. Genomic selection requires genomic control of inbreeding. Genet Sel Evol. 2012;44:27.

80. Pausch $H$, Wang $X$, Jung $S$, Krogmeier D, Edel C, Emmerling R, et al. Identification of QTL for UV-protective eye area pigmentation in cattle by progeny phenotyping and genome-wide association analysis. PLoS One. 2012; $7: e 36346$

81. Rincon G, Farber EA, Farber CR, Nkrumah JD, Medrano JF. Polymorphisms in the STAT6 gene and their association with carcass traits in feedlot cattle. Anim Genet. 2009;40:878-82.

82. Mészáros G, Eaglen S, Waldmann P, Sölkner J. A genome wide association study for longevity in cattle. Open J Genet. 2014;4:46-55.

83. Serao NV, Gonzalez-Pena D, Beever JE, Faulkner DB, Southey BR, Rodriguez-Zas SL. Single nucleotide polymorphisms and haplotypes associated with feed efficiency in beef cattle. BMC Genet. 2013;14:94.

84. Gibson AJ, Woodman S, Pennelegion C, Patterson R, Stuart E, Hosker $\mathrm{N}$, et al. Differential macrophage function in Brown Swiss and Holstein Friesian cattle. Vet Immunol Immunopathol. 2016;181:15-23.
85. Jann OC, Werling D, Chang JS, Haig D, Glass EJ. Molecular evolution of bovine Toll-like receptor 2 suggests substitutions of functional relevance. BMC Evol Biol. 2008;8:288.

86. Jann OC, King A, Corrales NL, Anderson SI, Jensen K, Ait-Ali T, et al. Comparative genomics of Toll-like receptor signalling in five species. BMC Genomics. 2009;10:216

87. Joerg H, Fries HR, Meijerink E, Stranzinger GF. Red coat color in Holstein cattle is associated with a deletion in the MSHR gene. Mamm Genome. 1996;7:317-8.

88. Kadri NK, Guldbrandtsen B, Lund MS, Sahana G. Genetic dissection of milk yield traits and mastitis resistance quantitative trait loci on chromosome 20 in dairy cattle. J Dairy Sci. 2015;98:9015-25.

89. Raven LA, Cocks BG, Goddard ME, Pryce JE, Hayes BJ. Genetic variants in mammary development, prolactin signalling and involution pathways explain considerable variation in bovine milk production and milk composition. Genet Sel Evol. 2014:46:29.

90. Tiezzi F, Parker-Gaddis KL, Cole JB, Clay JS, Maltecca C. A genome-wide association study for clinical mastitis in first parity US Holstein cows using single-step approach and genomic matrix re-weighting procedure. PLoS One. 2015;10:e0114919.

\section{Submit your next manuscript to BioMed Central and we will help you at every step:}

- We accept pre-submission inquiries

- Our selector tool helps you to find the most relevant journal

- We provide round the clock customer support

- Convenient online submission

- Thorough peer review

- Inclusion in PubMed and all major indexing services

- Maximum visibility for your research

Submit your manuscript at www.biomedcentral.com/submit 